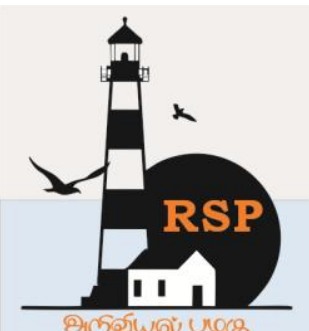

INTERNATIONAL RESEARCH JOURNAL ON ADVANCED SCIENCE HUB

RSP SCIENCE HUB

(The Hub of Research Ideas)

Available online at www.rspsciencehub.com

\title{
A Study on the effect of fairing designs of Go Kart on its performance using CFD analysis
}

Ezhil Ruban.L ${ }^{1}$, Infento Varun Kennet Thomas ${ }^{2}$, Leonard Maria Dicson .V ${ }^{3}$, Deugul B. $S^{4}$, Mahil H.M ${ }^{5}$

${ }^{1}$ Assistant Professor, Department of Mechanical Engineering, Loyola ICAM college of Engineering and Technology, Chennai, India

${ }^{2,3,4,5}$ Department of Mechanical Engineering, Loyola ICAM college of Engineering and Technology, Chennai, India.

\begin{abstract}
The primary purpose of the study focuses on the aerodynamic performance of Go Kart with optimized fairing designs using Computational fluid dynamics (CFD). CFD is a modelling technique for fluids which utilizes iterative methods to solve continuity and momentum equations as well as any other auxiliary equations depending upon the type of application. The computational simulations are carried out assuming the steady state viscous fluid flow using Reynolds-averaged-Navier-Stokes (RANS) equations and the standard shear stress transport (SST) $k$ - $\omega$. This paper studies the effect of the modified fairing on the overall aerodynamic performance of the kart such as the amount of drag force and down force generated at different speeds as well the coefficient of drag of the entire kart model $\left(C_{d}\right)$. Three models with different fairing designs were created using CAD software SOLIDWORKS 2018 and analyzed using ANSYS Fluent, the latter two models having optimized fairing designs. The aerodynamic behaviour of the three models Fairing $1,1.1 \& 1.2$ is observed at $60 \mathrm{kmph}$ and the simulated result indicates improved aerodynamic performance by both optimized fairings. Fairing 3 in particular exhibits nearly $48 \%$ decrease in drag force and a $10 \%$ decrease in $C_{d}$. This can offer a significantly better performance and reduced fuel consumption compared to the original design.
\end{abstract}

\section{Keywords: Fairing, Computational fluid dynamics, Drag force, Coefficient of drag, ANSYS Fluent.}

\section{Introduction}

When a vehicle is in motion, it has to overcome two major opposing forces, the rolling friction due to ground contact with the tires and fluid friction due to propagation through the air medium, also known as drag force. Drag force on the vehicle can have adverse effect on its performance as well as its fuel economy as most of the power goes to overcoming air resistance. About $80 \%$ of the drag force acting on the vehicle involves parasitic drag, a combination of pressure drag and skin friction drag. The pressure drag arises due to the shape of the vehicle and is represented by the drag coefficient value. Lesser the drag coefficient, lower is the air resistance and flow separation and its attendant vertices, which leads to turbulent flow along the vehicle surface. The employment of enclosures of the vehicle with improvised contours helped in reducing the air drag and improves the laminar flow. This ensured reduced drag which resulted in better efficiency and speed of the vehicle. The normal force that is experienced by vehicles while travelling through air was counter acted by contoured enclosures, in other words known as fairing. The design of said fairing focuses on enhancing the aerodynamic capabilities of the kart i.e. increasing the aerodynamic down force of the kart which improves stability at high 
www.rspsciencehub.com

speeds while at the same time avoid substantial increase in the drag force exerted on the body.[1-4]

The drag force $\left(\mathrm{F}_{\text {drag }}\right)$ and down force $\left(\mathrm{F}_{\text {down }}\right)$ produced in a vehicle is given by the following equations,

$$
\begin{aligned}
& F_{\text {drag }}=1 / 2 \rho C_{d} V^{2} A \\
& F_{\text {down }}=1 / 2 \rho C_{1} V^{2} A
\end{aligned}
$$

where $\rho$ is the density of air, A is the frontal area i.e. the area of the fairing; $\mathrm{V}$ is the velocity of the kart; $\mathrm{C}_{\mathrm{d}}$ is the drag coefficient and $\mathrm{C}_{1}$ is the coefficient of lift which has an inverse effect on the down force produced. The contour of the fairing is to be designed in such a way that there is minimum turbulence and little to no flow separation at the top surface of the fairing as the speed of the of the kart increases. Therefore a smooth and streamlined fairing is necessary for maximum efficiency. Apart from the original fairing, two separate fairings are designed in SOLIDWORKS, Fairing 1.1 and 1.2 respectively, and simulations are done to verify their performance. Using the models created, suitable simulations are carried out in ANSYS Fluent and the obtained computational results serve as an insight about the effect of well optimized fairing design on aerodynamic forces on the kart.[5-6]

\section{Design of Fairing Models}

The required models for the analysis were created using the CAD software SOLIDWORKS 2018. The techniques of solid modelling and surface modelling were used to complete the required fairing designs. The fairings were designed with a thickness of $2 \mathrm{~mm}$. While designing it is to be noted that the part has to be made into a single part before importing to ANSYS Fluent or the created assembly should have perfect mating conditions to process it into a single part in Design Modeler. Making the model directly as a single part will improve the efficacy of subtraction operation in Design Modeler. And finally after designing the models, they were saved using the STEP format as this format imports the models with solid elements as designed. Several other formats such as IGES, parasolid, SLDPRT etc. may result in shell elements which raise complications in Boolean operations.

\subsection{Existing fairing model - Fairing 1}

The existing fairing model i.e. Fairing 1 is based
Volume 02 Issue 09 September 2020

on the already existing fairing of go-kart at Loyola ICAM College of Engineering and technology.

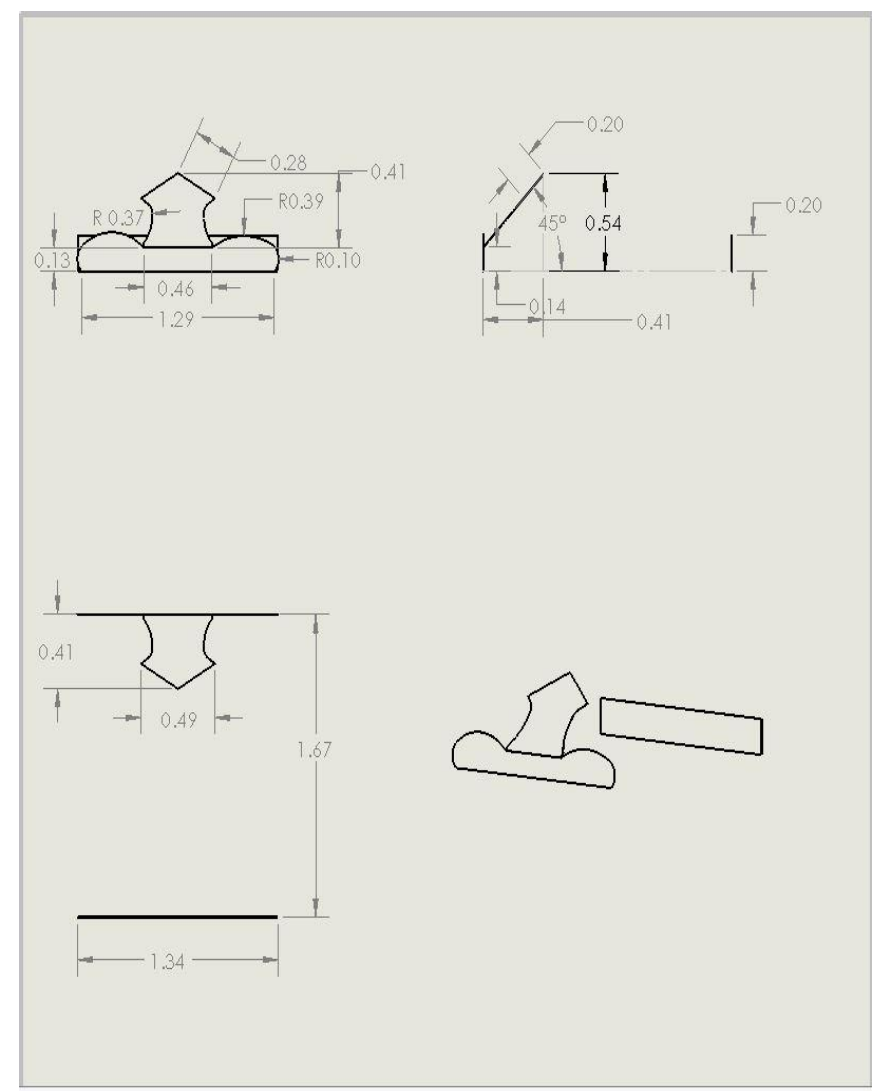

Fig.1. Orthographic Views of the Fairing 1 and rear diffuser of Go-kart at Loyola ICAM College of Engineering and Technology. - All dimensions are in meters.

\section{Fig.2. Isometric View of the Fairing 1 and rear diffuser model of existing Go-Kart}

The Fairing 1 model is integrated into the go-kart model to render a single part as opposed to a created assembly in-order to achieve perfect mating conditions before importing into ANSYS Fluent for the purpose of effective Boolean subtraction in the Design Modeler. Finer details such as suspension system, engine components and other accessories on-board the kart are not modelled partly due to their effect on the overall aerodynamic force 


\section{www.rspsciencehub.com}

coefficients, which is insignificant compared to other surfaces and also the inclusion of these parts into the kart model is greatly increase the complexity of the model which can lead to improper mating conditions and ineffective Boolean operations in the design Modeler which can lead to substantial deviations from the required values or fail to simulate altogether.

\subsection{Fairing model 1.1}

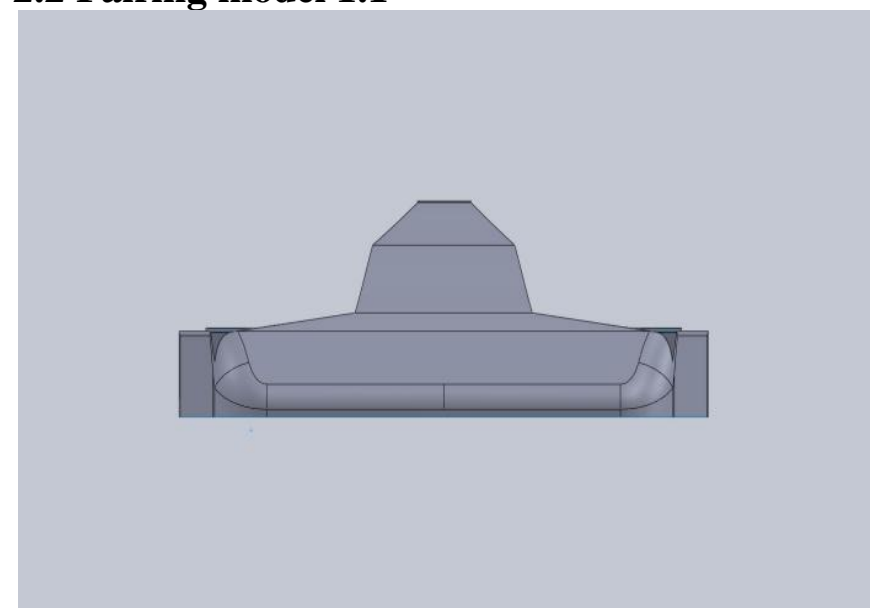

Fig.3. Front view of Fairing 1.1

The basic specifications of the Kart such as wheel base and trackwidth were set and intricate components such as brake calipers, tie rods, engine fixtures, engine plate, etc. were neglected from the design. The engine is replaced by a engine cover which was contoured to reduce the drag created by engine. The frame links that is situated behind and within the fairing were not considered in the design. The first design which has been implemented in the Go Kart sans CFD analysis was designed to analyze its performance and find out its caveats. The frontal area are potential factors for creating drag force, hence by analyzing the first design we found out that, immense drag is generated by the combined frontal area of the driver, whose shoulder and chest areas are directly exposed to air and are normal to the direction of flow, and the frontal area of the fairing which could also be reduced. The first fairing's contour can also be altered to enhance the kart's downforce.

\subsection{Fairing model 1.2}

In our second design we developed a fairing with a view to cover the driver's body (chest and shoulders) to an extent. On its analysis, we understood that the fairing's angle can be adjusted to reduce the frontal area to a little more extent.

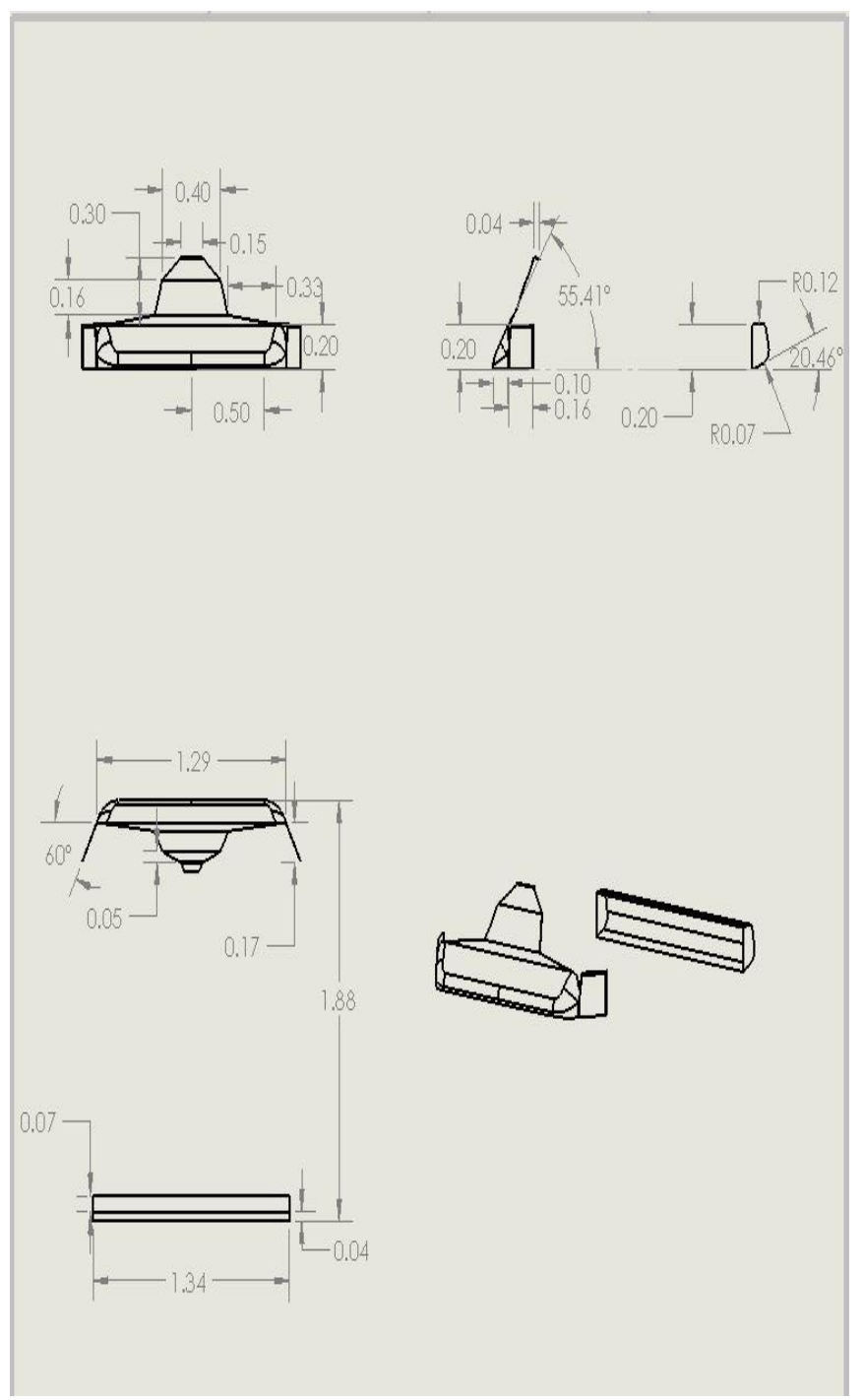

. Fig.4. Orthographic Views of Fairing 1.1 and rear diffuser. All dimensions are in meters.

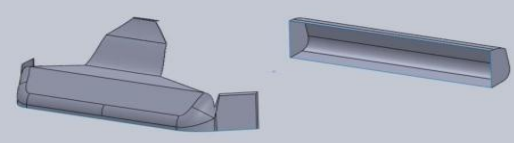
Fig.5. Isometric view of Fairing 1.1 and its
rear diffuser.

Hence while designing our final design we reduced the fairing angle while covering the driver's body. Apart from that we focused on the point where flow of air separates from fairing and ensured it to align with the driver's helmet. 


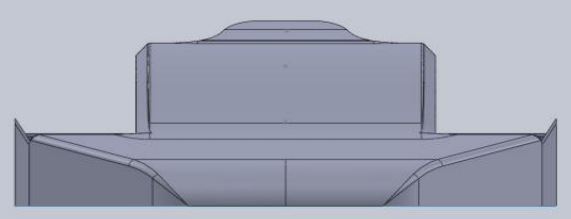

Fig.6. Front view of Fairing 1.2

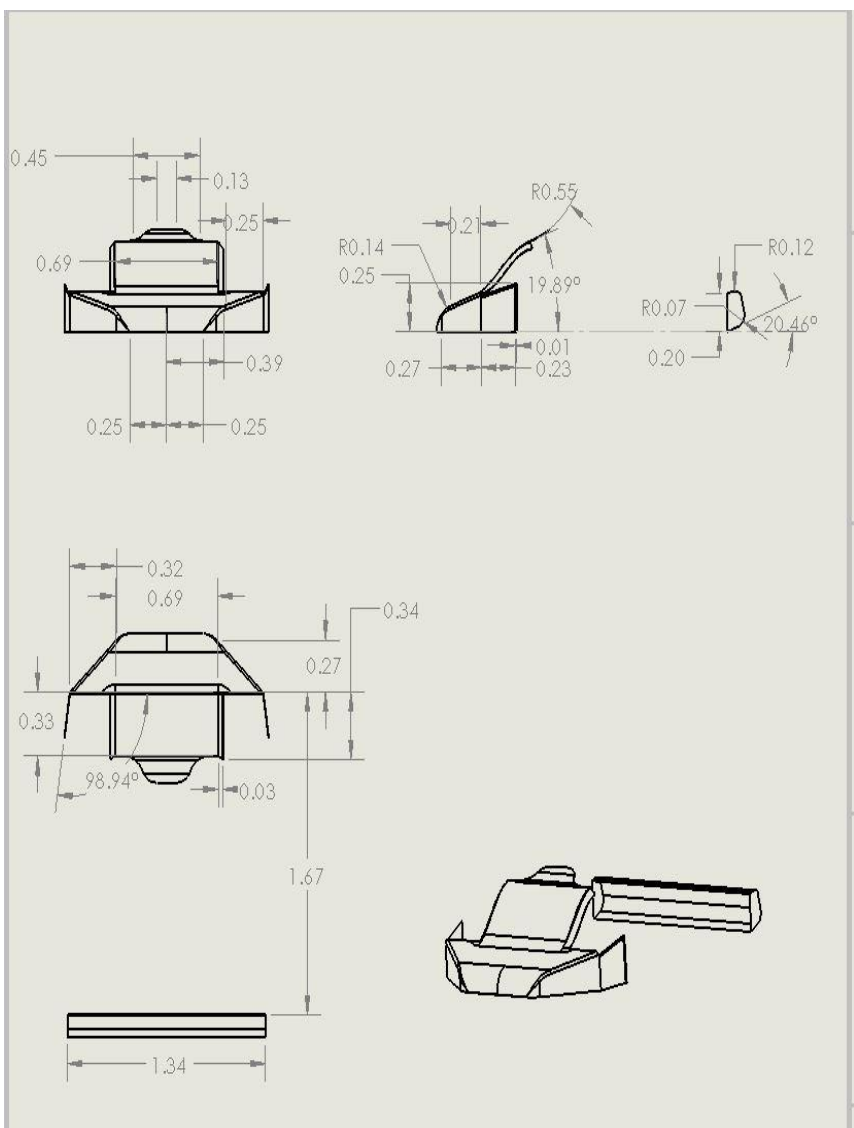

Fig.7. Orthographic Views of Fairing 1.2 and rear diffuser. All dimensions are meters.

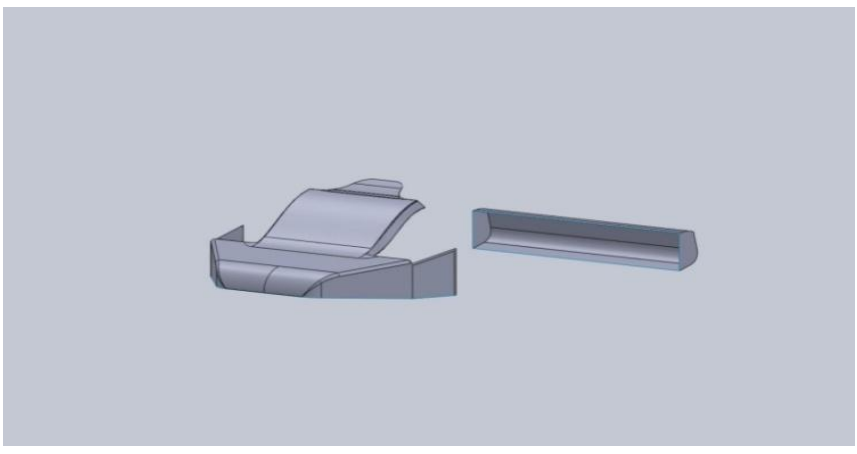

Fig.8. Isometric View of Fairing 1.2 and its rear diffuser.

\section{Analysis of the fairing models}

\subsection{Computational Setup}

The aim of this study is to analyze the effect of fairing and its design on aerodynamic force coefficient of a Go Kart. The computational setup was developed using ANSYS Fluent for stationary turbulent incompressible viscous flow. As the ANSYS Fluent is compatible with STEP format, the model that was created using Solid Works is saved with a .step extension. The computations are performed using Reynolds averaged Navier Stokes (RANS) equations.

a) Continuity Equation,

$$
\frac{\partial \bar{v}_{j}}{\partial x_{j}}=0,
$$

b) Momentum Equation,

$$
\begin{aligned}
& \frac{\partial}{\partial x_{j}}\left(\bar{v}_{j} \bar{v}_{i}\right)=-\frac{\partial \bar{p}}{\partial x_{i}}+\frac{\partial}{\partial x_{j}}\left[\mu\left(\frac{\partial \bar{v}_{i}}{\partial x_{j}}+\frac{\partial \bar{v}_{j}}{\partial x_{i}}\right)+\right. \\
& \mu \mathrm{t}\left(\frac{\partial \bar{v}_{i}}{\partial x_{j}} \cdot \frac{+\partial \bar{v}_{j}}{\partial x_{i}}\right)-\frac{2}{3} \rho \bar{k} \delta \mathrm{ij}
\end{aligned}
$$

Components of the averaged flow velocity are denoted as

$\bar{v}_{i}$, while $x_{i}$ are the coordinates, $\rho$ is the density, $\bar{p}$ is the averaged pressure, $\mu$ is the dynamic viscosity, $\mu \mathrm{t}$ is the turbulence viscosity, $k$ is the averaged turbulence kinetic energy. Virtually all engineering applications are turbulent and hence require a turbulence model. When turbulence is present, it usually dominates all other flow phenomena, which results in the energy dissipation, mixing, heat transfer and drag being increased. The Navier-Stokes equations govern the velocity and pressure of a fluid flow. The Reynolds-averaged Navier-Stokes (RANS) equation is obtained by averaging the equations which govern the mean flow. There is a closure problem which needs to be done to avoid the velocity fluctuations due to non-linearity of the Navier-Stokes equations. In turbulence modeling we only need to know the effect of turbulence on the mean flow. The standard k- $\omega$ turbulence model with shear stress transport (SST) is used together with the RANS model as this turbulence model has 
www.rspsciencehub.com

previously proved to be particularly suitable for studying kart aerodynamics.

Table.1. Initialization of the simulation procedure

\begin{tabular}{|c|c|}
\hline Solver & $\begin{array}{l}\text { Type: Pressure-based } \\
\text { Velocity formulation: } \\
\text { Absolute Time: Steady }\end{array}$ \\
\hline Models & $\begin{array}{l}\text { K- } \omega \text { SST turbulence } \\
\text { model }\end{array}$ \\
\hline Materials & $\begin{array}{l}\text { Fluid: Air } \\
\text { Solid :Polypropylene }\end{array}$ \\
\hline Boundary Conditions & $\begin{array}{l}\text { Inlet velocity: } 166.7 \mathrm{~m} / \mathrm{s} \\
\text { Pressure outlet: } 0 \text { (gauge } \\
\text { pressure) }\end{array}$ \\
\hline Methods & $\begin{array}{l}\text { Scheme: Simple } \\
\text { Gradient: Least squares } \\
\text { cell based Pressure : } \\
\text { Second order } \\
\text { Momentum : Second } \\
\text { orderupwind }\end{array}$ \\
\hline Controls & $\begin{array}{l}\text { Under-Relaxation factor } \\
\text { Pressure } \quad: 0.3 \\
\text { Density } \quad 1 \\
\text { Body Forces : } 1 \\
\text { Momentum :0.7 }\end{array}$ \\
\hline Initialization & $\begin{array}{l}\text { Initialization methods- } \\
\text { Standard Initialization } \\
\text { Compute from-Inlet } \\
\text { Reference Frame- } \\
\text { Relative to cell zone } \\
\text { Initial values-Y } \\
\text { Velocity }(\mathrm{m} / \mathrm{s})=-9.81\end{array}$ \\
\hline Run Calculation & $\begin{array}{l}\text { Number of Iterations - } \\
1000 \text { Reporting Interval- } \\
1 \text { Profile Update interval } \\
-1\end{array}$ \\
\hline
\end{tabular}

\subsection{Scaling}

The model is scaled to 0.1 times to its original size in order to reduce the mesh complexity increase accuracy. The model was selected and scaled by clicking Create from Design Modeler window. The dimensional scaling is done using Reynolds number. The study is done to analyse aerodynamic forces on the kart at $60 \mathrm{kmph}$ which is approximately $16.66 \mathrm{~m} / \mathrm{s}$.
Volume 02 Issue 09 September 2020

An enclosure is created in order to engineer the working fluid and implant a cavity for the object that is to be analyzed.

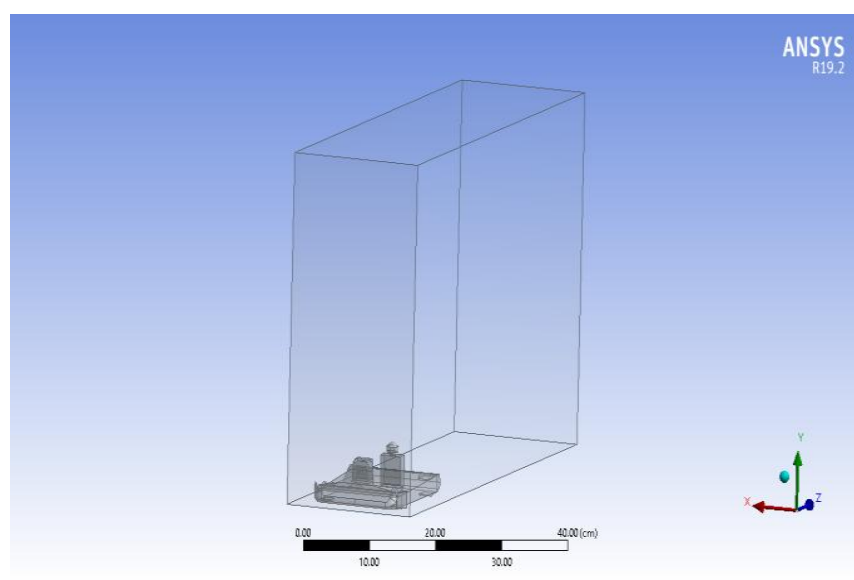

Fig.9. Computational Fluid Domain

The enclosure was constructed in such a way that the inlet was situated at a distance of $0.35 \mathrm{~m}$ from the model in actual size. The front plane is considered to be the inlet. The bottom plane was considered to be the wall. The other surfaces are determined to be outlets. The rear outlet was placed at a distance of $5 \mathrm{~m}$ in actual model. The side planes were created at a distance of $0.25 \mathrm{~m}$ from the model.

$$
\begin{aligned}
& \eta=\frac{\rho \times V \times L}{\mu} \\
& \frac{\rho_{a \times} V_{a \times} L_{a}}{\mu_{a}}=\frac{\rho_{m \times} V_{m \times L m}}{\mu_{m}} \\
& \because \mu_{a}=\mu_{m} \\
& \because \rho_{a}=\rho_{m} \\
& V_{a \times} L_{a}=V_{m} \times L_{m} \\
& V_{m}=\frac{V_{a \times} L_{a}}{L_{m}} \\
& \because L_{m}=0.1 L_{a} \quad(\text { As the scaling factor is } 0.1) \\
& V_{m}=\frac{V_{a \times} L_{a}}{0.1 L_{a}} \\
& V_{m}=V_{a} \frac{1}{0.1} \Rightarrow V_{m}=10 V_{a} \\
& V_{a}=16.667 \mathrm{~m} / \mathrm{s} \\
& V_{m}=10 \times 16.667 \Rightarrow 166.67 \mathrm{~m} / \mathrm{s}
\end{aligned}
$$

\subsection{Meshing}

A suitable mesh will give accurate and meaningful results. The area of interest has very high mesh 
www.rspsciencehub.com

density compared to the rest of the enclosure. The finer mesh is closer to the surface of the kart where the aerodynamic forces tend to act on.

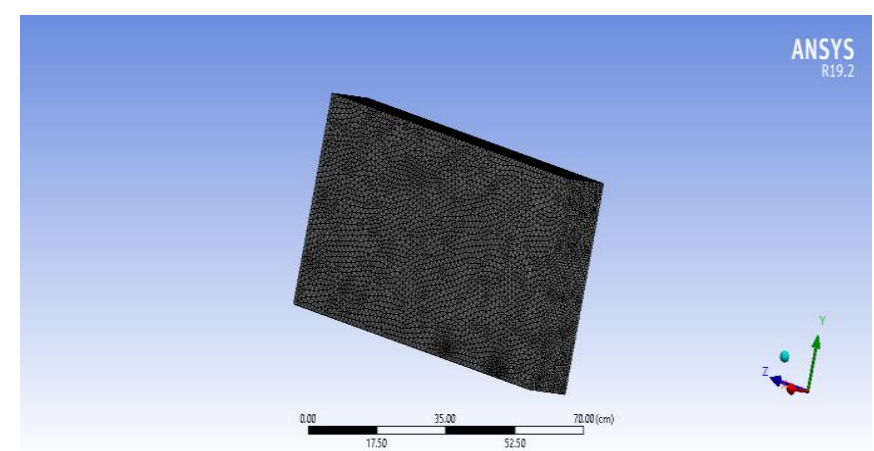

Fig.10. The enclosure after meshing

Table.2. Mesh Settings

\begin{tabular}{|l|l|}
\hline Physics Preference & CFD \\
\hline Solvent preference & Fluent \\
\hline Element order & Linear \\
\hline Element size & $2 \mathrm{~mm}$ \\
\hline
\end{tabular}

\subsection{Simulation Procedure}

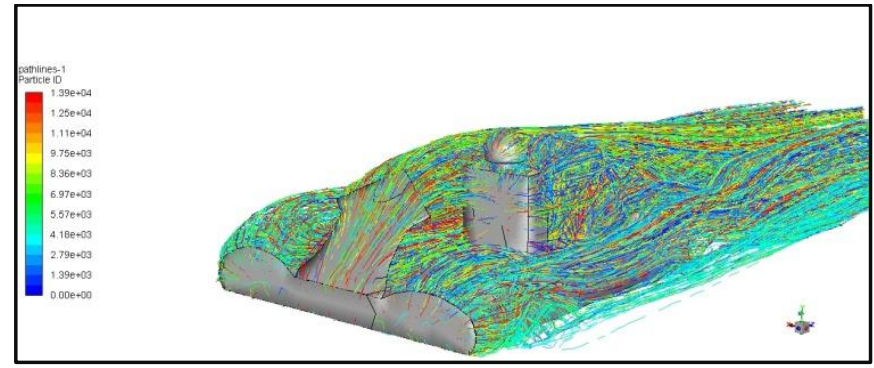

Fig.11. Flow Simulation on the Go-Kart with Fairing 1.0 - Pathlines

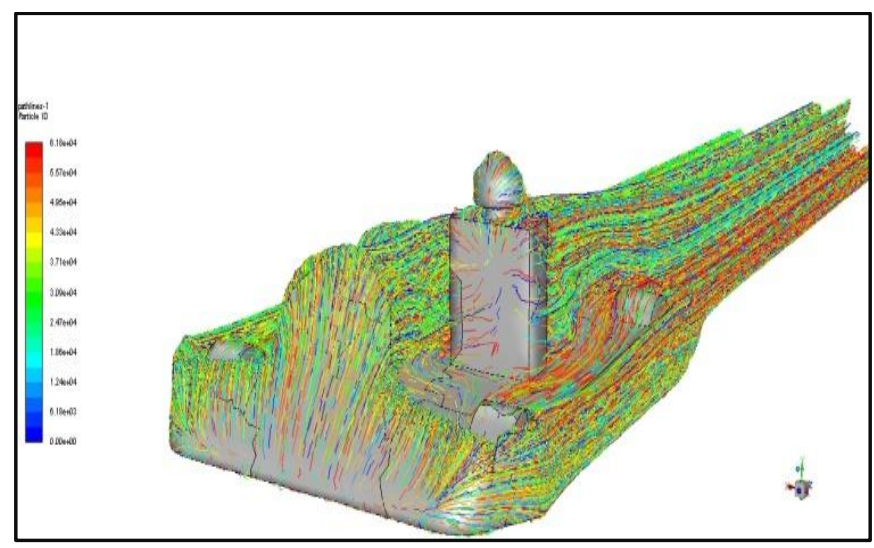

Fig.12. Flow Simulation on the Go-Kart with Fairing 1.1 - Pathlines

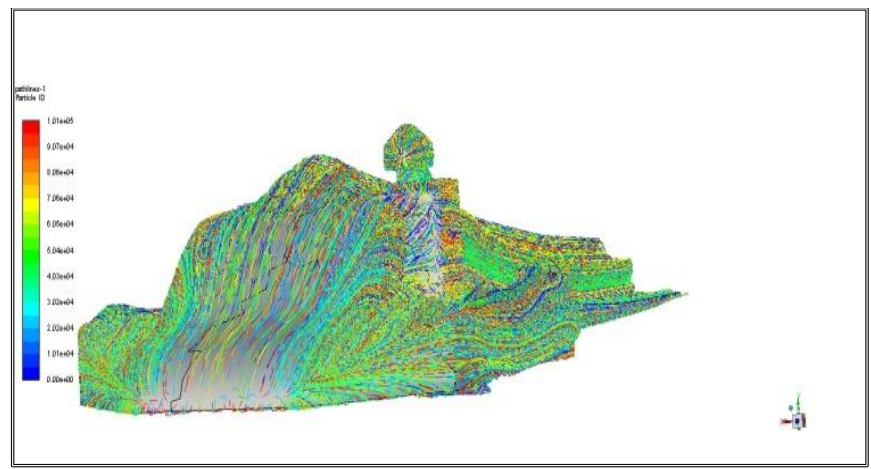

Fig.13. Flow Simulation on the Go-Kart with Fairing 1.2 - Pathlines

The simulation is carried out in ANSYS Fluent until convergence is achieved.

\section{Analysis and Inference}

The pressure contour, velocity contour and the path lines of Go Kart for all three fairing models are obtained in ANSYS FLUENT displayed below.

\subsection{Fairing 1 Performance}

The Go Kart with the original fairing design (Fairing 1.0) is subjected to steady state fluid flow at $60 \mathrm{kmph}$ or $16.667 \mathrm{~m} / \mathrm{s}$.

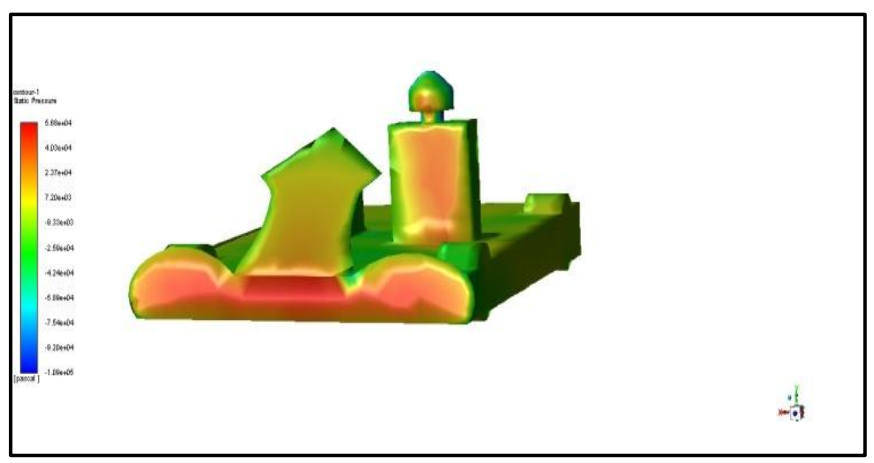

Fig.14. Static Pressure contour for Fairing 1.0

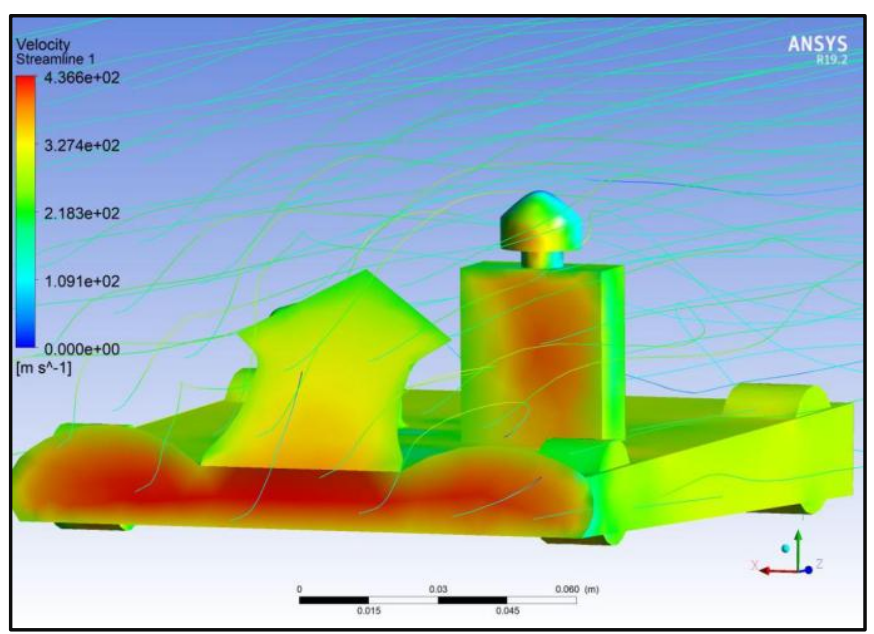

Fig.15. Velocity contour for Fairing 1.0 
www.rspsciencehub.com

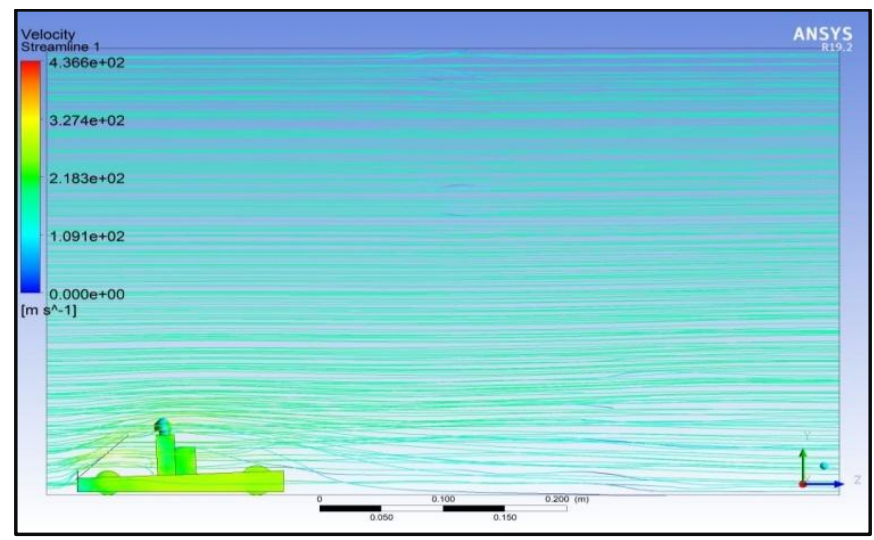

Fig.16. Velocity Contour for Fairing 1.0 - Side View

From the analysis, the following results are obtained.

Table.3 Output values for Fairing 1

\begin{tabular}{|r|r|l|}
\hline Drag Force (N) & $\begin{array}{l}\text { Coefficient of } \\
\text { Drag }\end{array}$ & $\begin{array}{l}\text { Down } \\
\text { Force (N) }\end{array}$ \\
\hline 212.31646 & 0.571 & -14.2117 \\
\hline
\end{tabular}

\subsection{Fairing 1.1 Performance}

The Go Kart with the Fairing design 1.1 is subjected to steady state fluid flow at $60 \mathrm{kmph}$ or $16.667 \mathrm{~m} / \mathrm{s}$.

\begin{tabular}{|c|c|c|}
\hline Drag Force (N) & $\begin{array}{l}\text { Coefficient of } \\
\text { Drag }\end{array}$ & $\begin{array}{l}\text { Down Force } \\
\text { (N) }\end{array}$ \\
\hline 201.61113 & 0.573 & 65.8007 \\
\hline
\end{tabular}

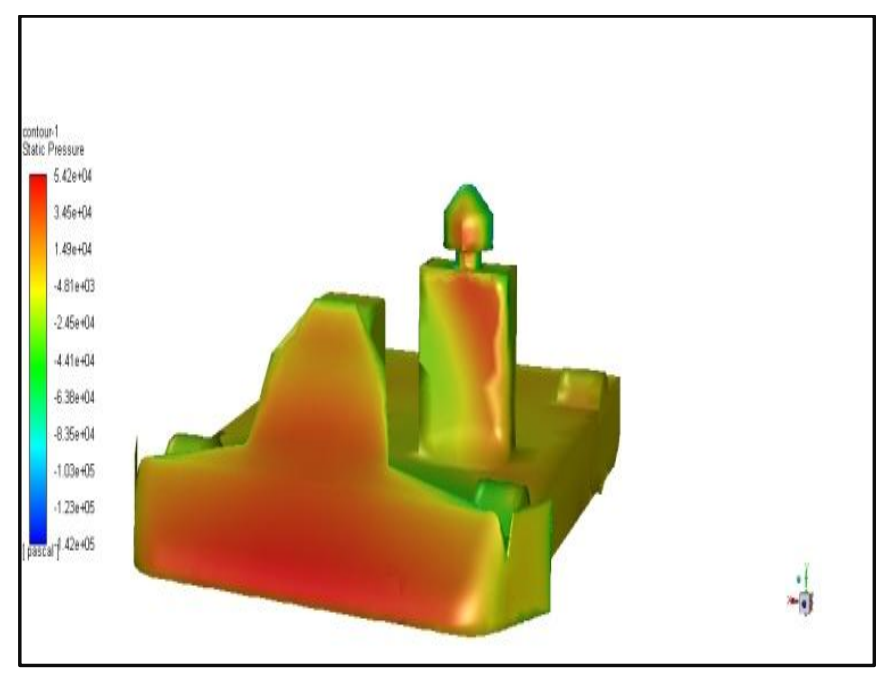

Fig.17. Static Pressure contour for Fairing 1.1

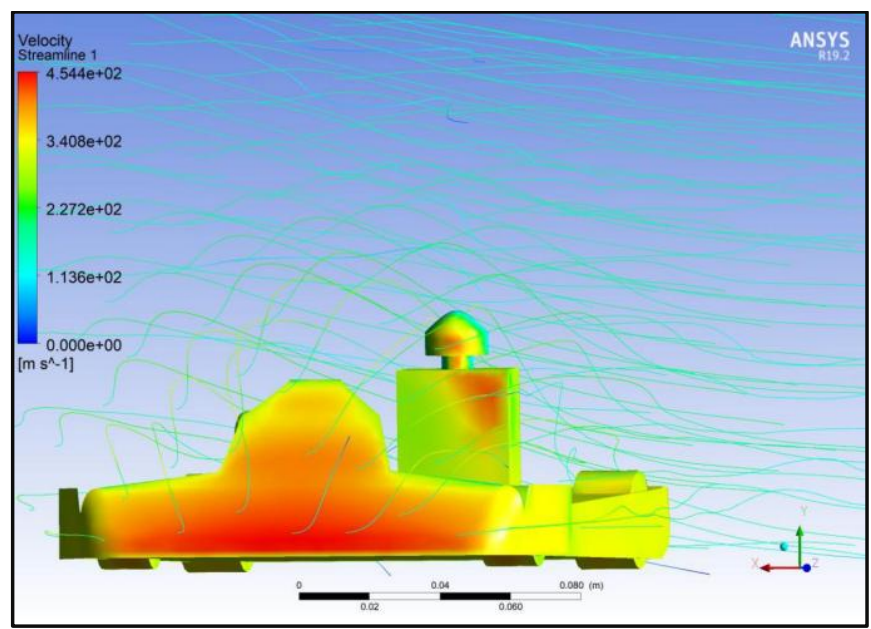

Fig.18. Velocity contour for Fairing 1.1

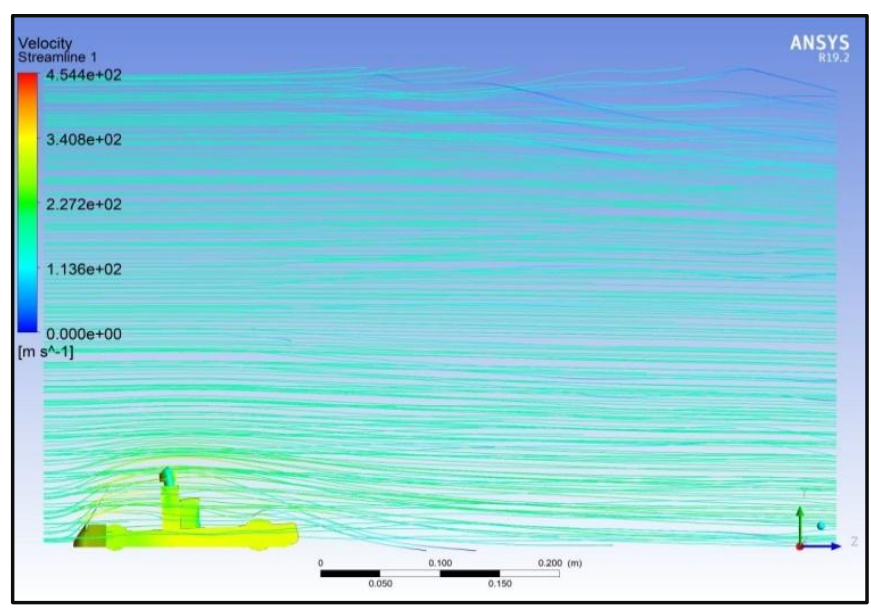

Fig.19. Velocity Contour for Fairing 1.1Side View

From the above analysis, the following results are obtained.

Table.4 Output Values for Fairing 1.1

\subsection{Fairing 1.2 Performance}

The Go Kart with the Fairing design 1.1 is subjected to steady state fluid flow at $60 \mathrm{kmph}$ or $16.667 \mathrm{~m} / \mathrm{s}$.

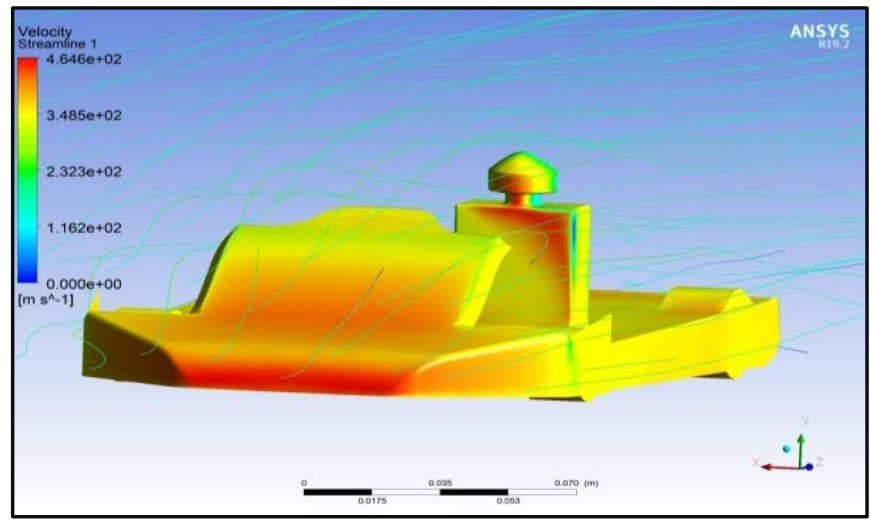

Fig.20. Static Pressure contour for Fairing 1.2 


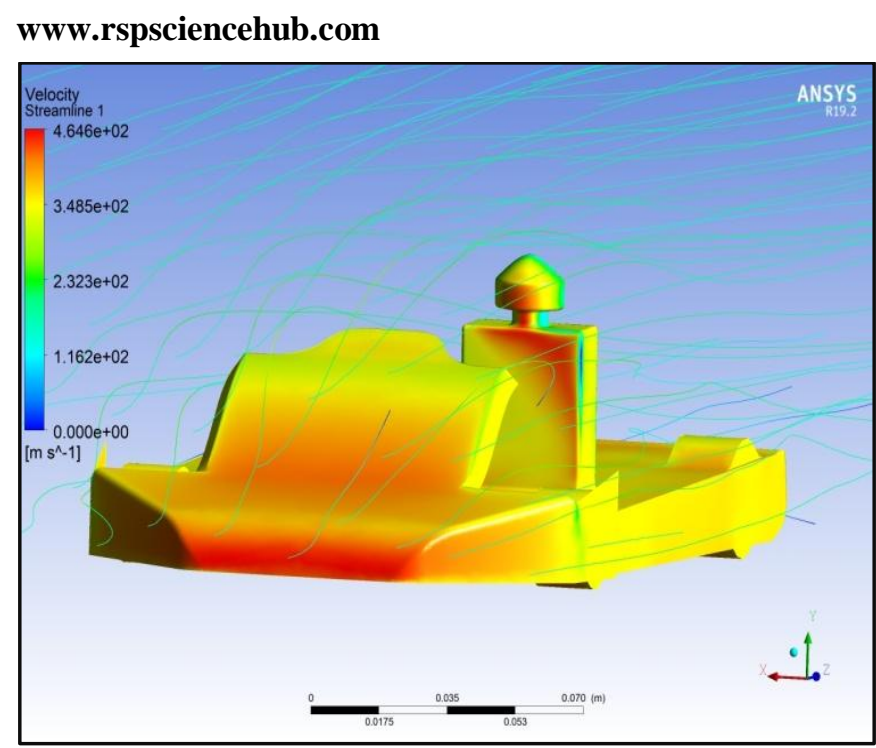

Fig.21. Velocity contour for Fairing 1.2

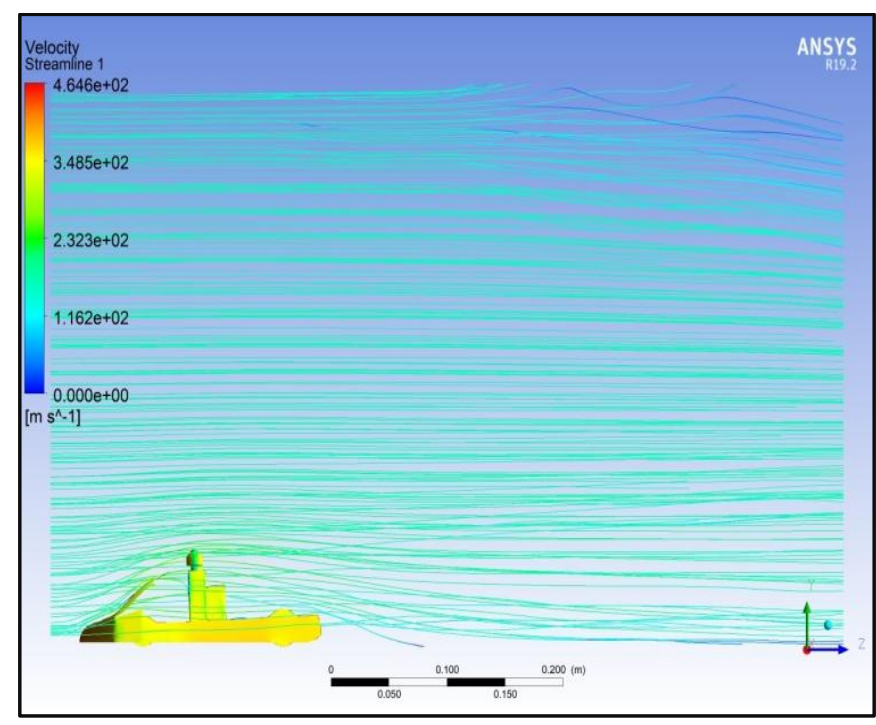

Fig.22. Velocity Contour for Fairing 1.2Side View

From the above analysis, the following results are obtained.

Table.5 Output Values for Fairing 1.2

\begin{tabular}{|l|l|l|}
\hline Drag Force (N) & $\begin{array}{l}\text { Coefficient of } \\
\text { Drag }\end{array}$ & $\begin{array}{l}\text { Down } \\
\text { Force (N) }\end{array}$ \\
\hline 111.33202 & 0.512 & 167.7741 \\
\hline
\end{tabular}

As we can see from the above simulations, we can infer that both fairings 1.1 and 1.2 have a much lower coefficient of drag compared to the existing fairing 1.0. Correspondingly there is a considerable reduction in the amount of drag force on the kart at $60 \mathrm{kmph}$ for both 1.1 and 1.2 compared to 1.0 while simultaneously increasing the amount of downforce generated.

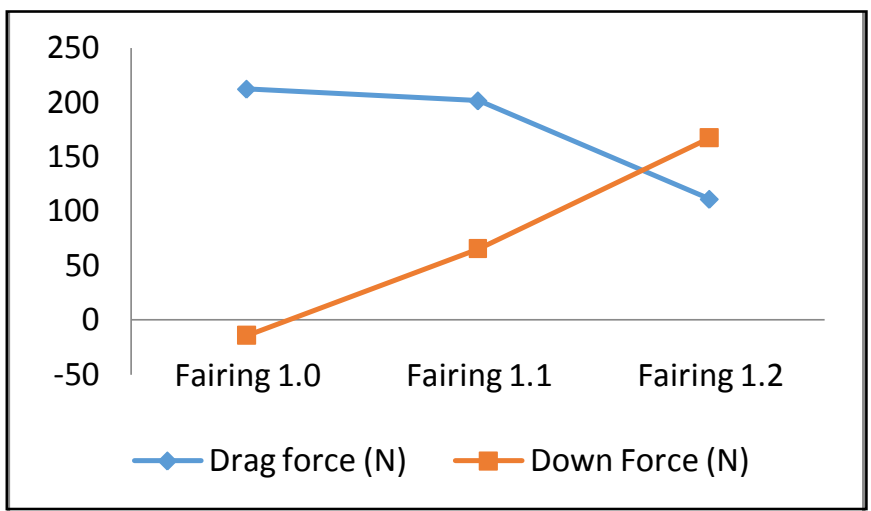

Chart.1. Drag force and down force generated by each fairing at $60 \mathrm{kmph}$. Note that both 1.1 and 1.2 improve on both aspects substantially.

The optimized fairing and rear diffuser combo can greatly enhance aerodynamic capabilities of the Go kart and helps in better performance, more stability at higher speeds due to increased downforce generation and lesser fuel consumption.

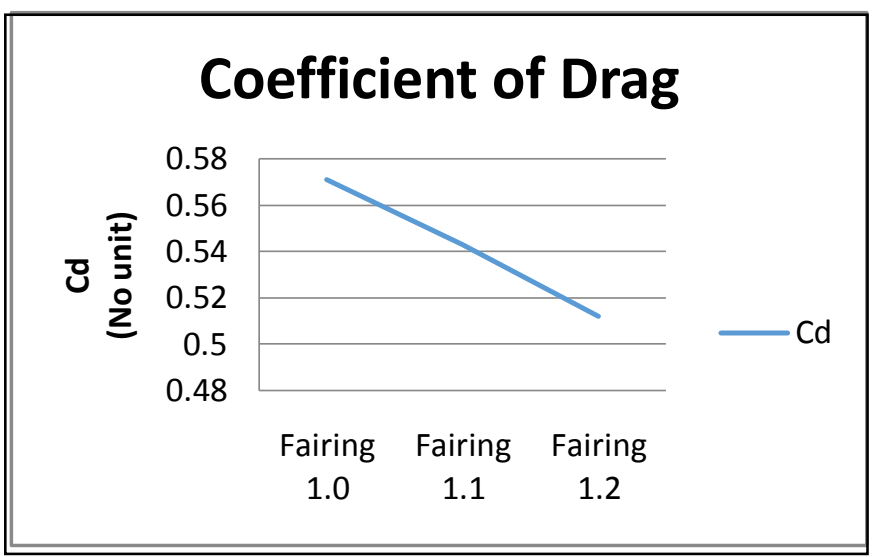

Chart.2. Comparison of $\mathbf{C}_{\mathrm{d}}$ for all three fairings.

A lower number $C_{d}$ corresponds to better aerodynamic performance.

Compared to existing Fairing 1.0, Fairing 1.1 has a percentage of reduction in drag force about $0.05 \%$. However, Fairing 1.2 improves on the previous design greatly by showing a marked improvement of $48 \%$ decrease in Drag force and $10 \%$ decrease in $\mathrm{Cd}$ over the existing 1.0 design. Real life $\mathrm{Cd}$ values of all three fairings however are liable to change considerably from simulated results so more wind tunnel experimental studies are suggested.

\section{Conclusion}

While raw performance of any racing car depends on its engine and power delivery components and suspension designs, a good aerodynamic design is more essential for the 
overall performance on track in terms of improved stability, higher top speeds and lesser fuel consumption. We have shown that optimized fairing and rear diffuser design has very large impact on the overall aerodynamic capabilities when it comes to open wheel race cars and thereby ensuring higher efficiencies if employed. Further real life studies are suggested to even improve over the current simulated results for a better optimized fairing for even better performance.

\section{References}

Journals

[1] Hassan, S.M. Rakibul (2013). Numerical Study on Aerodynamic Drag Reduction of Racing Cars. Procedia Engineering 90(2014), 308 - 313.

[2] Buljac, A. Aerodynamic performance of the Underbody and Wings of a Open Wheel Race Car. Transactions of FAMENA 40(2016), 19-34.

[3] Marco Evangelos Biancolini, An Integrated tool for competition Go-kart track

\section{Book} Analysis, "Tor Vergata" University, Rome.

[4] John D. Anderson Jr., Computational Fluid Dynamics the Basics with Applications, McGraw-Hill (1995).

[5] H. Versteeg, An Introduction to Computational Fluid Dynamics: The Finite Volume Method, 2nd Edition, Pearson (2007).

\section{Conference Proceedings}

[6] Marco Evangelos Biancolini, Evaluation of Aerodynamic drag of Go kart by means of Coast down test and CFD analysis, Global Motorsport Conference, Cologne, Germany (2007)November 5-6 